\title{
TURISMO ESPACIAL SOB A PERSPECTIVA MERCADOLÓGICA SOBRE O FUTURO DO RAMO A PARTIR DAS EXPERIÊNCIAS DA EMPRESA VIRGIN GALACTIC
}

\author{
Fábio Luciano Violin, Vitor Barbato Honorato
}

Universidade Estadual Paulista - UNESP, Curso de Turismo, Rosana, SP. E-mail: fabio.violin@unesp.br

\begin{abstract}
RESUMO
Este artigo apresenta breve introdução à história deste tipo de turismo para entender sua evolução, e apresenta uma análise de uma das empresas neste ramo atualmente, a Virgin Galactic. A pesquisa baseiase em levantamento de dados oriundos do website da organização bem como notícias a respeito da organização com foco na área turística dessa empresa. O estudo demonstrou que apesar da restrição à uma classe social elevada de potenciais usuários, a oferta vem aumentando e existe procura, as empresas estão procurando métodos para o barateamento das viagens e atingir um público maior. Concluiu-se que há mercado para atender diferentes formas de desejos, e apesar das diferenças entre elas, todas procuram a mesma coisa, levar a humanidade cada vez mais longe ao espaço.
\end{abstract}

Palavras-chave: Turismo, Mercadologia, Turismo Espacial.

\section{SPACE TOURISM UNDER THE MARKET PERSPECTIVE ON THE FUTURE OF THE INDUSTRY FROM THE EXPERIENCES OF THE COMPANY VIRGIN GALACTIC}

\begin{abstract}
This article presents a brief introduction to the history of this type of tourism to understand its evolution, and presents an analysis of one of the companies in this field currently, Virgin Galactic. The research is based on data collection from the organization's website as well as news about the organization focused on the tourism area of that company. The study showed that despite the restriction to a high social class of potential users, supply is increasing and there is demand, companies are looking for ways to lower travel and reach a larger audience. It was concluded that there is a market to meet different forms of desires, and despite the differences between them, they all look for the same thing, to take humanity ever further into space.
\end{abstract}

Keywords: Tourism, Marketing, Space Tourism.

\section{INTRODUÇÃO}

Até mesmo antes dos primórdios da corrida espacial a mente humana sempre foi povoada pela curiosidade e expectativa das viagens espaciais. A exploração espacial permitiu viagens cada vez mais distantes no espaço, como às estações espaciais e à Lua, com isso a curiosidade humana aumentou, juntamente com o desejo popular pela experiência nesse segmento. Filmes, livros, músicas e histórias romancearam a ida do homem ao espaço, e algumas empresas iniciaram a corrida pelo turismo espacial.

Esse estudo introdutório destaca a importância desse segmento, que a exemplo de outros modais de transporte tais como o aéreo, o ferroviário e o fluvial passaram em seu início pelo alto custo, necessidades de aprimoramento entre tantas atividades que os levaram ao longo do tempo a se tornarem populares, mas em seu início haviam restrições especialmente financeiras para seu consumo do ponto de vista mercadológico. Desse modo, justifica-se esse estudo considerando a potencialidade da área aliada ao desejo humano de consumo desse tipo de serviço.

Este artigo teve como objetivo destacar um novo mercado que está surgindo, oportunizando observar as atividades e a oferta de uma das empresas que fazem parte dessa corrida mercadológica além da busca pela difusão tecnocientífica da temática. 


\section{METODOLOGIA}

A corrida espacial com fins turísticos atualmente é disputada por três organizações: SpaceX, Virgin Galactic, e Blue Origin. Considerando as particularidades em da área, considerou-se que a exposição das ações de cada uma das empresas de modo isolado geraria a melhor forma de compreender suas ações, dado o espaço e o propósito do local ao qual se submete esse material.

Desse modo, optou-se pela análise das ações da Virgin Galactic como modo de exposição das estruturas de seu funcionamento e as atividades realizadas pela organização.

Sendo assim, esse estudo possui natureza qualitativa, com análise descritiva de informações oriundas de documentos da própria organização e também notícias sobre a área envolvendo a empresa. A estrutura de análise destaca: a empresa; o veículo; a proposta de experiência e alguns indicadores de mercado. Tendo como base central o website da empresa.

\section{RESULTADOS}

Mesmo vivendo na época das viagens espaciais há mais de meio século, a ida de seres humanos ao espaço continua sendo extremamente raro. Menos de 600 pessoas ultrapassaram a Linha de Kármán, ponto que fica por volta de 100 quilômetros da Terra e que marca o começo do espaço (THE AEROSPACE CORPORATION, 2018).

Entretanto, o crescimento de empresas privadas como SpaceX, Virgin Galactic e Blue Origin podem facilitar ultrapassar a maior barreira para a expansão desse tipo de turismo: 0 custo (HOWELL, 2018; MANN, 2017; MOLLOY, 2017).

O desenvolvimento dependerá através do tempo, partindo do ponto que todas as empresas já anunciaram seus projetos para voos turísticos espaciais. Inicialmente o custo de voos nessas espaçonaves seriam de, no mínimo, centenas de milhares de dólares. Isto faz com que o foco do mercado esteja nas pessoas com mais renda, que conseguem pagar a viagem e seu treinamento (SOLOMON, 2011).

Para isso, o avanço no desenvolvimento de foguetes e cápsulas é uma das principais metas para a viagem espacial se tornar mais acessível, mas ainda assim terá um enfoque mais restrito às classes sociais mais altas. Algumas projeções analisam que o mercado de turismo espacial pode chegar a mais de $\$ 34$ bilhões de dólares por volta de 2021 (BUSINESS WIRE, 2018).

\section{DISCUSSÕES \\ A EMPRESA}

A Virgin Galactic foi fundada em 2004 pelo grupo Virgin do Sr.Richard Branson. Seu objetivo é colocar turistas no espaço nos próximos anos. O CEO da Virgin Galactic, George Whitesides, comenta: "Estou inspirado que levaremos pessoas ao espaço para que elas consigam ter a experiência da observação, diz que muda sua perspectiva de visão do mundo de um modo fundamental" (VIRGIN GALACTIC, 2018).

A empresa planeja oferecer viagens suborbitais para o espaço, onde os clientes experimentarão alguns minutos de gravidade zero, juntamente com uma vista única. Os passageiros da Virgin Galactic serão lançados do Spaceport America, que é a primeira base espacial construída com o propósito comercial. Ela foi inaugurada no Novo México em 2011 (ROSTON, 2018).

"Enviar humanos ao espaço não só expandiu nosso conhecimento sobre a ciência, mas ensinou-nos coisas incríveis sobre a ingenuidade humana, psicologia e fisiologia. Do espaço, nós conseguimos olhar com uma nova perspectiva tanto para o exterior quanto para o interior. Do espaço, as fronteiras que estão em batalha são invisíveis. Do espaço é claro que há muito mais que nos une do que nos divide." (VIRGIN GROUP, 2018).

\section{O VEículo e o VoO}

A Virgin Galactic utiliza o VSS Unity, um sistema de voo espacial reutilizável. Ele consiste no White Knight Two, um avião de quatro motores movido a jato projetado para levar o Space Ship Two a uma altitude de aproximadamente quinze mil metros. $O$ conceito de lançamento dos veículos espaciais ao ar primeiramente, e depois ao espaço, é ideal aos voos comerciais espaciais por questões de segurança, experiência dos passageiros e eficiência do combustível (VIRGIN GALACTIC, 2018).

A Space Ship Two é uma espaçonave reutilizável, com asas anexas, projetada para levar seis passageiros e dois pilotos ao espaço em segurança e com alta velocidade. Ela é movida por um motor híbrido (combina elementos de foguetes sólidos e líquidos). A vantagem de um 
motor híbrido é a junção do poder de um motor com combustível sólido, com o controle do líquido. Uma das funcionalidades da SpaceShipTwo é a capacidade de mudar sua forma no espaço para uma reentrada segura, colocando suas asas e cauda para cima, fazendo com que a estabilidade e a desaceleração na reentrada para a Terra seja controlada por forças aerodinâmicas. (VIRGIN GALACTIC, 2018).

A cabine da Space Ship Two foi projetada para a experiência de máximo conforto e segurança para os astronautas. Os assentos são articuláveis e a cabine é espaçosa: seu interior foi feito especificamente para otimizar a experiência de gravidade zero e da observação do espaço, devido a espaçonave ter o maior número de janelas comparada a qualquer outra na história (VIRGIN GALACTIC, 2018).

\section{A EXPERIÊNCIA}

Os turistas que desejarem se aventurar pela Virgin Galactic passarão por um programa de treinamento pré-voo na base espacial onde serão lançados que durará 3 dias. Durante este treinamento, cada astronauta irá aprender como aproveitar a maior parte do tempo em microgravidade, bem como aprender a ficar confortável e seguro durante os períodos de alta velocidade. Os treinamentos vão garantir que cada astronauta esteja mental e fisicamente preparado para aproveitar cada segundo do seu voo espacial.

O White Knight Two irá subir a uma altitude de aproximadamente quinze mil metros até soltar o Space Ship Two, espaçonave que levará os passageiros até a parte final da viagem. Ela então realizará a queima do seu combustível pelo motor por cerca de um minuto até os pilotos o desligarem, a velocidade chegará aproximadamente 3 vezes e meia a mais que a velocidade do som, dando propulsão ao veículo para atingir uma altitude de 110 quilômetros da Terra, acima da Linha de Kármán (VIRGIN GALACTIC, 2018).

Virgin Galactic, colocou "tendo acabado de experienciar uma eletrizante viagem de foguete, a dramática transição para o silêncio e a para a verdadeira leveza será um momento marcante para os nossos astronautas..." (VIRGIN GALACTIC, 2018).

Após isso os passageiros deixarão seus assentos para experimentar a verdadeira gravidade zero. Os pilotos irão manobrar a nave para que os passageiros tenham as melhores vistas possíveis da Terra e da escuridão do espaço enquanto a espaçonave configura suas asas na posição de reentrada. Depois de alguns minutos, os passageiros retornarão aos seus assentos customizados que proporcionarão conforto durante a reentrada. Aos quinze mil metros do chão as asas da espaçonave voltarão a sua configuração normal, que são projetadas para planar de volta ao Spaceport America, para um pouso suave. A experiência inteira dura em torno de duas horas (VIRGIN GALACTIC, 2018).

\section{O MERCADO}

Mais de 700 pessoas já se inscreveram até agora para os voos espaciais da Virgin Galactic, tais pessoas são originárias de mais de cinquenta nações, sendo que mais da metade dessas nações nunca colocou o homem no espaço, e, das que colocaram mais que uma dúzia ainda não fez a viagem com uma mulher de astronauta (MOLLOY, 2017)

Menos que 600 pessoas viajaram acima da atmosfera terrestre, e a Virgin pretende mudar isso. Os inscritos vão de jovens até idosos e eles vêm de vários lugares. Entre os inscritos estão celebridades como Brad Pitt, Ashton Kutcher, Angelina Jolie, Tom Hanks e Paris Hilton (VIRGIN GALACTIC, 2018).

Um assento no voo custa por volta de 250 mil dólares, que deverá ser pago em um depósito adiantado. "Eu pessoalmente acredito que a perspectiva planetária será crucial para solucionar os maiores problemas da humanidade nos próximos séculos" diz o CEO, George Whitesides (ROSTON, 2018).

A Virgin Galactic tem acordos comerciais com alguns parceiros que são críticos para a realização dessas viagens espaciais, são eles: Land Rover, companhia automotiva que providenciará veículos para a equipe nas bases espaciais da Virgin, para ajudar com o transporte dos astronautas. A Microsoft Edge, outro parceiro que ajudou a criar uma experiência exclusiva aos que participarão dos voos da Virgin (VIRGIN GALACTIC, 2018).

\section{CONCLUSÃO}

A partir deste levantamento introdutório é possível inferir que o mercado de turismo espacial se apresenta em desenvolvimento, observando que a demanda mercadológica por voos da Virgin Galactic, já ultrapassaram a casa das 700 reservas, pode-se concluir que, mesmo 
em fase de desenvolvimento, o mercado se mostra promissor.

Existem ao menos três grandes empresas empenhadas nessa corrida: Blue Origin, SpaceX e a Virgin Galactic - empresa aqui analisada. Nesse sentido, pode-se apontar que existe, por parte da empresa analisada esforço contundente e deliberado no sentido de alavancar o novo negócio.

Destaca-se o papel dos investidores representa de modo deliberado a força estrutural externa necessária para o apoio e a estruturação consistente da oferta em momento vindouro, e que segundo a evolução observada, com a alta demanda provocada pela curiosidade ou desejo da experiência por parte de potenciais consumidores representa relevante volume, tal fato tem despertado a atenção e investidores e a Virgin Galactic tem tido tal apoio.

o estudo das experiências proporcionadas aos turistas atualmente por essa empresa demonstrou que o que existe de fato nesse momento ainda é limitado, reduzindo-se ao turismo suborbital, sempre com a mesma dinâmica de voo. Porém as empresas estão desenvolvendo novos veículos para oferecer diferentes destinos. As expectativas são para viagens cada vez mais longas, proporcionando às turistas experiências nunca vivenciadas antes dentro de um mercado promissor segundo as experiências e investimentos apresentados pela própria Virgin Galactic.

\section{REFERÊNCIAS}

HOWELL, E. (Ed.). New Shepard: Rocket for Space Tourism. Space. 2018. Disponível em: <https://www.space.com/40372-new-shepardrocket.html>. Acesso em: 12 jun. 2018.

MANN, A. (Ed.). So you want to be a space tourist?: Here are your options virgin Galactic, SpaceX, and blue origin are just three of the companies poised to offer space missions to private astronauts. NBC News, 2017. Disponível em:

$<$ https://www.nbcnews.com/mach/science/soyou-want-be-space-tourist-here-are- youroptions-ncna784166>. Acesso em: 10 mar. 2018.

MOLLOY, M. (Ed.). What is Virgin Galactic and how much will it cost to travel to space? 2017. Telegraph. Disponível em: <https://www.telegraph.co.uk/technology/0/virg in- galactic-much-will-cost-travel-space/>. Acesso em: 17 abr. 2018.

ROSTON, M. (Ed.). Rocket Launches and Trips to the Moon We're Looking Forward To in 2018. New York Times, 2018.Disponível em: <https://www.nytimes.com/2018/01/01/science/ 2018-spacex-moon.html>. Acesso em: 22 abr. 2018.

SOLOMON, L. D. The privatization of space exploration: business, technology, law and policy. Washington: Transaction Publishers, 2011. 128 p.

THE AEROSPACE CORPORATION.A Brief History of Space Exploration. California: Aerospace, c2018. Disponível em: <http://www.aerospace.org/education/stemoutreach/space-primer/a-brief-history-of-spaceexploration/>. Acesso em: 20 abr. 2018.

VIRGIN GALACTIC. Learn. 2018. Virgin Galactic. Disponível em: <http://www.virgingalactic.com/learn/>. Acesso em: 18 abr. 2018.

BUSINESS WIRE. Top 3 Emerging Trends Impacting the Global Space Tourism Market from 2017-2021: Technavio. Disponível em: <https://www.businesswire.com/news/home/20 170616005756/en/Top-3-Emerging-TrendsImpacting-Global-Space>. Acesso em: 11 jul. 2018.

Recebido para publicação em 08/05/2018

Revisado em 24/08/2018

Aceito em 20/09/2018 